\section{Transtorno de identidade de gênero (TIG) e orientação sexual}

\section{Gender identity disorder and sexual orientation}

\section{Caro Editor,}

O transtorno de identidade de gênero (TIG) - ou transsexualismo - caracteriza-se por uma forte identificação com o gênero oposto, por um desconforto persistente com o próprio sexo e por um sentimento de inadequação no papel social deste sexo. Trata-se de uma condição que causa um sofrimento psicológico clinicamente significativo e prejuízos no funcionamento social, ocupacional ou em outras áreas importantes da vida de um indivíduo ${ }^{1}$.

Desde a última metade do século XX, os avanços científicos têm favorecido o estudo deste transtorno, a maior aceitação social e a possibilidade de um tratamento integral orientado a redesignação sexual. Apesar disso, continua sendo pouco conhecido pela maior parte da sociedade, incluindo os profissionais da saúde mental.

Para realizar o diagnóstico, é preciso diferenciar os termos identidade de gênero e orientação sexual. A identidade de gênero refere-se à consciência de um indivíduo de ser homem ou mulher. A orientação sexual relaciona-se com a atração erótica, podendo ser homossexual, heterossexual, bissexual ou assexual. Os transexuais podem apresentar qualquer uma destas orientaçôes ${ }^{1}$.

Recentemente, atendemos na Unidade de Gênero do Hospital Clinic de Barcelona (UIG) um paciente de 51 anos que há três anos recebeu o diagnóstico de TIG homem-mulher. Desde pequeno gostava de brincadeiras femininas e, inclusive, sua mãe o tratava como menina. Devido à forte repressão do pai, acabou restringindo suas tendências femininas. Aos 14 anos, começou a namorar uma menina. Logo no início confessou que se sentia como uma mulher e ela entendeu e o apoiou. Aos 23 anos se casaram. Em casa, o paciente se vestia como mulher e as relações sexuais com penetração eram esporádicas e desagradáveis para ele, acontecendo apenas para agradar sua esposa. Aos 32 anos tiveram uma filha. Desde a juventude ocupa um cargo administrativo no serviço público e manteve papel social masculino devido ao desconhecimento, rechaço social e falta de serviços assistenciais na época. Aos 48 anos, época em que a UIG foi fundada, procurou o serviço. Iniciou o teste da vida real ${ }^{1}$ e, posteriormente, o tratamento hormonal, assumindo progressivamente o papel social feminino. Depois de dois anos, foi submetido à vaginoplastia. Atualmente, encontra-se muito satisfeita com a resignação. Tem boa aceitação social, laboral, familiar e mantém a relação matrimonial. A esposa afirma que sua orientação sexual é por homens, que não se considera lésbica, e que mantém seu casamento por uma questão afetiva. O paciente refere que sua orientação sexual é e sempre foi por mulheres.
A orientação sexual para o sexo biológico contrário ou bissexual não é um critério de exclusão para o diagnóstico do TIG. Na população espanhola, apenas uma minoria dos transexuais homem-mulher apresentam uma orientação sexual por mulheres $(4,4 \%)$ ou bissexual $(4,4 \%)$, porcentagem similar às das brasileira e asiática ( 0 a $4 \%)$ e menores que as européias e americanas (33\% a $91 \%)^{2-4}$. No grupo de mulher-homem, a porcentagem que apresenta uma orientação sexual por homem é praticamente nula $(0 \%)$ e a de bissexuais, baixa $(2,8 \%)$, coincidindo com as outras ${ }^{2}$.

Conclui-se que, apesar da orientação sexual para o sexo biológico oposto dificultar o diagnóstico diferencial do TIG, não o descarta. Além disso, esta discussão destaca a importância do diagnóstico correto do TIG, assim como a possibilidade de acesso ao tratamento na rede pública, uma vez que são poucos os serviços habilitados no Brasil 5 .

Alexandre Costa Val, Ana Paula Souto Melo Instituto Raul Soares, Fundação Hospitalar do Estado de Minas Gerais (FHEMIG), Belo Horizonte, MG, Brasil

Iria Grande-Fullana, Esther Gómez-Gil Hospital Clinic, Departamento de Psiquiatria, Barcelona, Espanha 
Financiamento e conflito de interesse

\begin{tabular}{|c|c|c|c|c|c|c|c|}
\hline $\begin{array}{l}\text { Membro do grupo } \\
\text { de autores }\end{array}$ & $\begin{array}{l}\text { Local de } \\
\text { trabalho }\end{array}$ & $\begin{array}{l}\text { Verba de } \\
\text { pesquisa }\end{array}$ & $\begin{array}{c}\text { Outro apoio à } \\
\text { pesquisa ou educação } \\
\text { médica continuada }^{2}\end{array}$ & $\begin{array}{c}\text { Honorários } \\
\text { de } \\
\text { palestrantes }\end{array}$ & $\begin{array}{l}\text { Participação } \\
\text { acionária }\end{array}$ & $\begin{array}{l}\text { Consultorl } \\
\text { conselho } \\
\text { consultivo }\end{array}$ & Outro $^{3}$ \\
\hline Alexandre Costa Val & $\begin{array}{l}\text { Instituto Raul } \\
\text { Soares }\end{array}$ & - & - & - & - & - & - \\
\hline Iria Grande-Fullana & $\begin{array}{l}\text { Hospital } \\
\text { Clinic, } \\
\text { Barcelona }\end{array}$ & - & - & - & - & - & - \\
\hline $\begin{array}{l}\text { Ana Paula Souto } \\
\text { Melo }\end{array}$ & $\begin{array}{l}\text { Instituto Raul } \\
\text { Soares }\end{array}$ & - & - & - & - & - & - \\
\hline Esther Gómez-Gil & $\begin{array}{l}\text { Hospital } \\
\text { Clinic, } \\
\text { Barcelona }\end{array}$ & - & - & - & - & - & - \\
\hline
\end{tabular}

* Modesto

** Significativa

*** Significativa. Montantes fornecidos à instituição do autor ou a colega onde o autor tem participação, não diretamente ao autor. Mais informações, consultar as Instruções aos Autores

Referências

1. Gómez-Gil E, Esteva de Antonio I. Ser transexual (Being Transsexual). Barcelona: Glosa; 2006

2. Gómez-Gil E, Trilla A, Salamero M, Godás T, Valdés M. Sociodemographic, clinical, and psychiatric characteristics of transsexuals from Spain. Arch Sex Behav. 2009;38(3):378-92.

3. Lawrence AA. Societal Individualism Predicts Prevalence of Nonhomosexual Orientation in Male-to-Female Transsexualism. Arch Sex Behav [Internet]. 2008. [cited 2009 Dec 20]. Available from: http://www.ncbi. nlm.nih.gov/pubmed/19067152

4. Lobato MI, Koff WJ, Manenti C, da Fonseca Seger D, Salvador J, da Graça Borges Fortes M, Petry AR, Silveira E, Henriques AA. Follow-up of sex reassignment surgery in transsexuals: a Brazilian cohort. Arch Sex Behav. 2006;35(6):711-5.

5. Arán M, Murta D, Lionço T. Transsexuality and public health in Brazil. Cien Saude Colet. 2009;14(4):1141-9. 